\title{
LA FINANCIACIÓN DE LA COMUNIDAD VALENCIANA. LA SOSTENIBILIDAD DEL GASTO SANITARIO: PROBLEMAS ACTUALES
}

\section{THE FINANCING OF THE VALENCIAN COMMUNITY. THE SUSTAINABILITY OF THE SANITARY EXPENSE: CURRENT PROBLEMS}

\author{
ANA MARÍA LÓPAZ PÉREZ*
}

Recibido: 04/05/2017

Aceptado: 20/09/2017

SUMARIO: 1. INTRODUCCIÓN. 2. ESTADO DE LA CUESTIÓN DE LA FINANCIACIÓN AUTONÓMICA. LA FINANCIACIÓN DE LA COMUNIDAD VALENCIANA. PROPUESTAS DE SOLUCIÓN. 2.1. ESTADO DE LA CUESTIÓN DE LA FINANCIACIÓN AUTONÓMICA. 2.2. LA FINANCIACIÓN DE LA COMUNIDAD VALENCIANA. TENDENCIAS REFORMISTAS. 3. LA SOSTENIBILIDAD DEL GASTO SANITARIO. PROBLEMAS ACTUALES. 4. A MODO DE CONCLUSIÓN. 5. BIBLIOGRAFIA.

SUMMARY: 1. INTRODUCTION. 2. STATE OF THE QUESTION OF THE REGIONAL FINANCING. THE CASE OF THE VALENCIAN COMMUNITY. PROPOSED SOLUTIONS. 2.1. STATE OF THE QUESTION OF THE REGIONAL FINANCING. 2.2. THE VALENCIAN COMMUNITY FINANCING. REFORM TRENDS. 3. THE SUSTAINABILITY OF THE HEALTH EXPENDITURE. CURRENT ISSUES. 4. CONCLUSIONS. 5. BIBLIOGRAPHY.

Resumen: La financiación autonómica, objeto de numerosas discusiones en nuestra clase política, se halla en un escenario de continuo debate; el modelo de 2009 es incapaz de dar respuesta a las necesidades de las Comunidades Autónomas de reducción del déficit. La Comunidad Valenciana, con un alto nivel endeudamiento, no resulta beneficiada con el actual sistema; su gasto sanitario es cada vez mayor. En el presente trabajo estudiaremos el estado de la financiación de las CCAA, de la Comunidad Valenciana en especial y sus tendencias reformistas. Asimismo, abordaremos el problema del gasto sanitario y de su sostenibilidad, del concierto y de su futura viabilidad.

Palabras clave: financiación autonómica, Comunidad Valenciana, gasto sanitario, sostenibilidad, concierto sanitario

Abstract: Regional financing that has been being subjected to numerous discussions in our political class, is in a stage of ongoing debate; the financing model, which was approved in 2009, is unable to respond to the needs of deficit reduction of the autonomous communities. Valencian Community, with a high debt level, is not being

* Profesora doctora, acreditada ayudante doctor. Florida Universitaria (Adscrita a la Universitat de València). Área de Derecho Financiero y Tributario. e-mail: alopaz@florida-uni.es. Código ORCID: 0000-0001-6825-4080. 
benefited with the current system; its health care spending has been growing enormously. In our study, we will analyze the current situation of financing of the autonomous regions, especially the Valencian Community situation. We will also study the problem of health expenditure, its sustainability, and the future viability of health care contracts.

Keywords: Valencian Community, autonomous financing, health spending, financial sustainability, health care contracts.

\section{INTRODUCCIÓN}

De entre todos los temas objeto de discusión en nuestro país en los últimos años, sin duda la financiación de las Comunidades Autónomas (en adelante CCAA) es uno de los que merece capítulo aparte por varias razones; en primer lugar porqué desde la aprobación de la Ley Orgánica de Financiación de las Comunidades Autónomas (en adelante LOFCA) en 1980 no se ha procedido a una reforma en profundidad de la misma; en segundo lugar porque las reformas estatutarias acaecidas desde el año 2006 muestran un clima de descontento generalizado en el que los entes subcentrales reclaman mayores cuotas de autonomía y el Estado central permanece ajeno a sus pretensiones; la reforma del Estatuto de Cataluña es todo un ejemplo de ello ${ }^{1}$. Y finalmente porque la crisis económica y financiera que comenzó en España en el año 2007, cuyos desbastadores efectos seguimos padeciendo, puso de manifiesto que el modelo actual de financiación autonómica no ha conseguido sus objetivos primordiales y en consecuencia, su revisión no puede ni ignorarse ni demorase por más tiempo.

A lo anterior hay que añadir el espinoso tema de la cuestión soberanista acontecido en la Comunidad de Cataluña en la que se reivindica y reclama el Derecho de esta CCAA a la independencia y por tanto a su reconocimiento como nación soberana. En este punto y por el momento, ya que los acontecimientos en torno a la reivindicación de independencia no dejan de sucederse, el Tribunal Constitucional(en adelante TC) responde de manera muy acertada: buena prueba de ello es la Sentencia del Tribunal Constitucional (en adelante STC) 32/2015, de 25 de febrero de 2015 al declarar la inconstitucionalidad del Decreto 129/2014, de 27 de septiembre, de convocatoria de la consulta popular no referendaria sobre el futuro político de Cataluña; la sentencia 42/2014, de 25 de marzo, en relación con la impugnación de la Resolución del Parlamento de Cataluña 5/X de 23 de enero de 2013 y la sentencia de 2 de diciembre de 2015 que resuelve el recurso interpuesto por el Gobierno contra la resolución del Parlamento de Cataluña 1/XI, de 9 de noviembre de 2015, sobre el inicio del proceso

\footnotetext{
${ }^{1}$ No olvidemos que el texto de la ponencia del Estatuto de Autonomía de Cataluña y el finalmente aprobado por las Cortes Generales difieren en cuestiones "conflictivas" como la consideración de Cataluña como nación o la atribución a esta CCAA de un poder judicial propio. En la cuestión de la financiación, la propuesta del Gobierno de Cataluña se fundamenta en el aumento de la capacidad de gestión dotando a la Generalitat de capacidad normativa y responsabilidad fiscal para gestionar los impuestos estatales. El texto aprobado por las Cortes suaviza dicha capacidad y se decanta por la técnica de la delegación estatal en aras a su puesta en práctica. Vid en este punto Lópaz Pérez, A. (2009). La Sentencia del Tribunal Constitucional (en adelante STC) 31/2010, de 28 de junio de 2010, resuelve por fin y tras muchos años de espera, el recurso de inconstitucionalidad interpuesto contra la reforma del Estatuto de Autonomía de Cataluña. Vid Lópaz Pérez (2014) en Adame Martínez; Ramos Prieto (2014).
} 
político en Cataluña como consecuencia de los resultados electorales del 27 de septiembre de 2015. Si bien es cierto que para entender el origen de las reivindicaciones por parte de esta CCAA debemos de remontarnos a su reforma estatutaria de 2006 y a la sentencia del Alto tribunal que resuelve el recurso de inconstitucionalidad, interpuesto con ocasión de la citada reforma. El Tribunal en su sentencia de 28 de junio de 2010 afirma que las referencias efectuadas en el Preámbulo del estatuto de Autonomía (en adelante EEAA) sobre “Cataluña como nación” y "la realidad nacional de Cataluña” no tienen en ningún caso eficacia interpretativa. La citada STC declara nulos y por tanto inconstitucionales, entre otros, los siguientes preceptos: el inciso "y con la participación del Consejo de Justicia de Cataluña” del articulo 95.5; los articulo 97 y ss. por los que se crea y atribuyen competencias al citado Consejo de Justicia de Cataluña; el inciso "como principios o mínimo común normativo en normas con rango de ley, excepto en los supuestos que se determinen de acuerdo con la Constitución y el presente Estatuto" del articulo 111; el inciso "siempre y cuando lleven a cabo un esfuerzo fiscal también similar" del articulo 206.3 relativo a la participación en el rendimiento de los tributos estatales y mecanismos de nivelación y solidaridad; el inciso "puede incluir la capacidad legislativa para establecer y regular los tributos propios de los gobiernos locales" del articulo 218.2 en lo referente a la autonomía y competencias financieras de las haciendas de los Gobiernos locales ${ }^{2}$.

En suma, nos hallamos ante un escenario que muestra una realidad social compleja, formando parte de un Estado en el que los gobiernos regionales reclaman mayores cuotas de autonomía y algunos, por ende, de independencia. Debemos preguntarnos si dichas pretensiones entran en contradicción con los principios recogidos en la Constitución e incluso dar un paso más y reflexionar si el modelo de Estado diseñado en nuestra Carta Magna tiene fecha de caducidad; estas y otras cuestiones encontrarán respuesta en nuestras futuras investigaciones.

Por lo que atañe al sistema de financiación autonómica, se halla regulado en los artículos 156 a 158 y en la LOFCA. El modelo de financiación aprobado en 2001 por el Consejo de Política Fiscal y Financiera (en adelante CPFF) nacido con clara vocación de permanencia fue modificado en 2009; el nuevo modelo aboga por la real convergencia entre los entes autonómicos e introduce correcciones financieras en aras a la aproximación de la financiación per cápita de la que cada Comunidad Autónoma es receptora; asimismo, pretende tomar en consideración su capacidad fiscal y beneficiar las inversiones de las CCAA que disponen de menor renta per cápita y que cuentan con una dinámica poblacional menos favorecida.

La realidad es que, tras sucesivas reuniones y acuerdos del CPFF, como el acontecido el de 6 de marzo de 2012 por el que se fijan las líneas generales de un mecanismo extraordinario de financiación para el pago a los proveedores de las Comunidades Autónomas, aun no se ha logrado conseguir el objetivo de disminución del elevado déficit en el que se hallan inmersas las CCAA de Régimen Común; al contrario, mucho nos tememos, y sin pretender caer en el alarmismo, que la situación es cada vez más preocupante.

\footnotetext{
${ }^{2}$ Vid Lópaz Pérez (2016).
} 
La última y VI Conferencia de Presidentes Autonómicos celebrada el 17 de enero de 2017 considera muy oportuno impulsar el proceso de actualización del sistema de financiación autonómica en aras a la adopción de medidas en pro de un sistema garante de financiación suficiente, de acuerdo con los principios de solidaridad, suficiencia, equidad, transparencia y corresponsabilidad fiscal. Por todo ello se acuerda constituir una Comisión de Expertos, (integrada miembros propuestos por el Estado y CCAA). Dicha Comisión emitirá los informes y análisis necesarios para la elaboración de nuevos modelos de financiación autonómica y local. Asimismo, y esto sí constituye una novedad, se pretende analizar el ejercicio de la corresponsabilidad fiscal en nuestro país.

En lo que a atañe a la Comunidad Valenciana, un nuevo modelo de financiación es propuesto por una Comisión de expertos nombrados por las Cortes Valencianas, el 16 de septiembre de 2013, con la pretensión de eliminar "asimetrías" existentes entre CCAA e incrementar el espacio fiscal propio y la corresponsabilidad fiscal ${ }^{3}$. El informe elaborado por la Comisión arroja cifras devastadoras: la Generalitat Valenciana se encuentra en una evidentemente grave y difícil situación financiera, el déficit del ejercicio de 2012 ascendía a 3.513 millones de euros (el 25\% del presupuesto anual de gastos). La deuda acumulada en el primer trimestre de 2013 supone 29.037 millones de euros (5.900 euros por habitante; más de dos veces el presupuesto de la Generalitat y el 29\% del PIB valenciano) el mayor porcentaje entre todas las Comunidades Autónomas.

La Generalitat ocupa la última posición en ingresos per cápita durante la última década, debido principalmente a que el sistema de financiación autonómica proporciona financiación por habitante sustancialmente menor que la media. El déficit continuado al que se enfrenta es el reflejo de una evidente contradicción; por una parte un comportamiento financiero en cierto modo prudente, capaz de evitar el alarmante endeudamiento y, por otra, la prestación de un nivel de servicios semejante al de las demás CCAA. Si obtuviera una financiación per cápita igual a la media de las comunidades de régimen común la Generalitat Valenciana debería recibir 205 euros más por habitante y año, lo que representa más de 1.000 millones de euros anuales adicionales (datos de liquidación de 2011, última publicada). Así pues, el efecto que ocasiona la menor financiación podría explicar gran parte del déficit y la deuda pública valenciana. De haber tenido lugar la obtención y el poder de disposición de los mencionados recursos y efectuado el mismo nivel de gasto ejecutado, se podría haber prevenido la práctica totalidad del endeudamiento que fue acumulado durante la fase en que la economía de la Comunidad Valenciana se hallaba en expansión. Otro factor que hemos de añadir a lo anteriormente expuesto es la constante disminución de ingresos fiscales en los últimos cinco años, factor que contribuye en buena medida al aumento del déficit público.

Con base en todo lo anteriormente expuesto, la justificación de las razones por las cuales hemos elegido la Comunidad Valenciana como objeto de estudio son obvias:

\footnotetext{
${ }^{3}$ Criterios y propuestas para un nuevo sistema de financiación autonómica. Documento elaborado por la Comisión de expertos nombrados por las Cortes Valencianas, 16 de septiembre de 2013. Págs. 57-65. Disponible en http://www.ivie.es/downloads/2013/09/PP-criterios-propuestas-nuevo-sistemafinanciacion-autonomica.pdf . Fecha de consulta: 17/03/2017.
} 
la grave situación de endeudamiento en la que se encuentra en relación con el resto de CCAA; la sucesión de modificaciones legislativas y de propuestas para cambiar su sistemas de financiación que vienen acaeciendo en los últimos dos años, clara consecuencia de cambios y vaivenes políticos; el delicado momento por el que atraviesa el estado de la financiación de la sanidad, que se verá reflejado inevitablemente en las formas de gestión de sus servicios públicos y por último, por ser esta Comunidad Autónoma nuestra residencia.

En suma, el objetivo del presente trabajo es el análisis del estado de la financiación autonómica, particularmente en la Comunidad Valenciana, desde la perspectiva de los ingresos; estudiaremos también la situación actual del gasto de la sanidad y su futura sostenibilidad. En cumplimiento del citado objetivo, y tras una introducción, trataremos del estado de la cuestión de la financiación autonómica. Tras ello, centraremos nuestra atención en Comunidad Valenciana, inmersa en un escenario reformista, y su situación actual. Posteriormente dedicaremos un apartado al escenario del gasto sanitario, en el que trataremos el concierto como forma de gestión de los servicios públicos. Llegaremos por último a las conclusiones, fruto de nuestro trabajo.

\section{ESTADO DE LA CUESTIÓN DE LA FINANCIACIÓN AUTONÓMICA. LA FINANCIACIÓN DE LA COMUNIDAD VALENCIANA. PROPUESTAS DE SOLUCIÓN.}

\section{1- Estado de la cuestión de la financiación autonómica.}

La voluntad de la construcción del estado de las autonomías encuentra su origen en la voluntad del legislador constituyente, fruto del consenso de todas las fuerzas políticas de la transición democrática ${ }^{4}$. El estado autonómico esbozado en sus orígenes en nuestra Carta Magna emerge lleno de ambigüedades e incertidumbres; en consecuencia, las disposiciones normativas que contribuyeron a su formación necesitaron continuas modificaciones y sufrieron ciertos vaivenes legislativos hasta su asentamiento definitivo. García Morillo; Pérez Tremps; Zornoza Pérez (1998) afirman que el Estado Autonómico es una creación de la Constitución además un "precipitado histórico" formado por las disposiciones normativas del llamado bloque de constitucionalidad. De ellas, las concernientes a la financiación de los entes autonómicos destacan por sí mismas. Ello viene a significar, siempre según estos autores, que nos hallamos ante una "noción constitucional” inmersa en el bloque de la constitucionalidad, del sistema de financiación autonómica.

La originaria LOFCA aprobada en 1980, norma que establece el sistema de financiación autonómica, fue reformada once años más tarde por la Ley Orgánica 7/2001, de 27 de diciembre; la citada norma destaca, bajo nuestro punto de vista, por la ampliación del principio de corresponsabilidad; principio consensuado y aprobado por el CPFF en ese mismo año; su incremento se pretende a través de la cesión de nuevos tributos estatales a las CCAA, así como también con la concesión de mayores competencias normativas en los tributos cedidos por el Estado.

\footnotetext{
${ }^{4}$ Resulta lectura obligada que arroja luz a este apasionante episodio de nuestra historia reciente es la obra de Tudela Aranda (2016).
} 
Con respecto a la primera de las medidas comentadas introducida por la Ley de 2001 (la ampliación del principio de corresponsabilidad fiscal) y tras otras modificaciones operadas en LOFCA ${ }^{5}$ puede observarse lo siguiente: en los años de la crisis económica la capacidad decisoria sobre el IRPF (impuesto que mayores niveles de recaudación presenta) que ostentan las CCAA no es tanta como en un principio parecía preverse; la justificación de este hecho se encuentra según Zubiri (2016) en el cierre "de facto" por parte del Gobierno central de los espacios fiscales pertenecientes a las CCAA; con respecto al IRPF la percepción por parte de los entes autonómicos en impuestos indirectos o en las tarifas ha sido mínima. Consecuentemente, las CCAA adolecen de capacidad fiscal real.

Desde la perspectiva de los gastos, Cuenca García (2014) observa un avance significativo de la corresponsabilidad fiscal de las CCAA desde 1987 sin embargo, reclama un refuerzo de los mecanismos que hacen efectivo el principio así como las necesarias limitaciones con respecto a la autonomía en el gasto. De no ser así, nuestro sistema hoy de fuerte arraigo en la descentralización de los servicios públicos, podría caer en la ineficiencia y la insostenibilidad financiera.

En relación con la segunda medida citada, la ampliación de competencias normativas a las CCAA sobre los tributos cedidos, los cambios introducidos a través de las reformas legislativas han consistido básicamente en modificaciones de la tarifa general, modificaciones de la deducción general por vivienda habitual o inclusión de modificaciones en la cuota, Lópaz Pérez (2009).

Con respecto a los modelos que regulan el sistema de financiación, como dijimos en la introducción, el modelo aprobado en 2001, que nace con vocación de permanencia, y el posterior modelo de 2009 no han sido capaces de corregir las deficiencias del sistema y disminuir el déficit de las CCAA. Tanto es así, que en la actualidad la VI Conferencia de Presidente se plantea reformar el modelo vigente en la actualidad mediante el análisis de los actuales mecanismos de financiación y por medio de un sistema fundado en los principios de solidaridad, suficiencia, equidad, transparencia, corresponsabilidad fiscal y garantía de acceso de los ciudadanos a los servicios públicos en función del coste efectivo de los mismos.

En aras a establecer las deficiencias del actual modelo, no podemos menos de citar el excelente trabajo realizado por Zubiri (2016), y cuyas conclusiones pueden resumirse del modo siguiente: uno de sus mayores deficiencias es la falta de transparencia, debido en gran parte a la existencia de multitud de fondos y subfondos que no hacen sino añadir dificultad a la comprensión y justificación del resultado

\footnotetext{
${ }^{5}$ La originaria LOFCA de 1980 ha sufrido además de la modificación efectuada en 2001 las siguientes: las establecidas mediante la Ley Orgánica 3/2009, de 18 de diciembre y la Ley Orgánica 2/2012, de 27 de abril, de Estabilidad Presupuestaria y Sostenibilidad Financiera. La Ley 3/2009 introduce dos principios fundamentales: la garantía de un nivel base equivalente de financiación de los servicios públicos fundamentales; de acuerdo con este principio, los recursos financieros para la prestación de los servicios básicos del Estado del Bienestar deben servir para que éstos puedan ser prestados en igualdad de condiciones a todos los ciudadanos, independientemente de la Comunidad Autónoma en la que residan. Por otro lado, la corresponsabilidad de las Comunidades Autónomas y el Estado, en consonancia con sus competencias en materia de ingresos y gastos; nada nuevo bajo el sol. Por su parte la Ley 2/2012 supone el efectivo cumplimiento del mandato contenido en el reformado artículo 135 de la CE en el año 2011.
} 
distributivo (entre otros); otro de sus grandes defectos es la "recaudación normativa" cuya medición no puede considerarse acertada en algunos elementos que forman parte del concepto, y finalmente la falta de real capacidad efectiva.

El siguiente paso es el planteamiento de soluciones a los problemas o deficiencias del sistema, y ¿cuáles son las propuestas que existen actualmente en este sentido? Autores como Granell (2016) abogan por un sistema basado en la transparencia ante quejas de CCAA como Baleares, Cataluña o Comunidad Valenciana que presuntamente soportan, y que no es tal en opinión de este autor, una excesiva presión fiscal o por la excesiva solidaridad, que de nuevo presuntamente, se les exige a estas Comunidades.

Zubiri (2016) propone la división de los recursos en dos bloques; uno redistributivo y otro con base territorial; al primer bloque pueden incluirse servicios fundamentales y su reparto se efectuaría en proporción a la población. En el segundo bloque tendría lugar la inclusión de los recursos en proporción al lugar de origen.

Delgado Téllez y Pérez. J. (2016) ponen de manifiesto la necesidad de efectuar un debate en conjunción con otros temas como la normativa de estabilidad presupuestaria, concretamente el marco de mecanismos de prevención y resolución de crisis fiscales; las instituciones que gobiernan la coordinación de las políticas fiscales entre gobierno central y CCAA; el papel del endeudamiento autonómico.

Por último, Villalta (2016) expone, entre otras ideas, con respecto al Fondo de Garantía de los Servicios Públicos fundamentales (FGSPF) ${ }^{6}$ que tan importante como la metodología de su cálculo es tener un mecanismo adecuado para que funcione correctamente.

Esta misma autora, consciente de la posición, en su opinión discriminatoria, de la Comunidad de Cataluña en el actual modelo, contempla distintas vías de solución; tales como la aceptación por parte de esta CCAA de la posibilidad de revisión del modelo vigente, en el que participaría activamente para discutir su mecanismo nivelador; la puesta en marcha de la negociación bilateral entre el Gobierno de Cataluña y el Gobierno central sobre una posible introducción de ciertas especificidades para Cataluña, sin salir del modelo general y con la aprobación de un pacto fiscal capaz de introducir un modelo con características similares al establecido para País Vasco y Navarra o el cumplimiento de la hoja de ruta del actual gobierno de la Generalitat; hecho que implica desde el punto de vista político, la declaración de independencia del Estado de Catalunya antes de julio del 2017 (hecho que evidentemente ya no puede producirse). Sin embargo, en contra de lo que en principio pudiera pensarse, tal declaración supone la permanecía, que no la exclusión, de Cataluña en el modelo de financiación del Estado.

\footnotetext{
${ }^{6}$ Regulado en el artículo 9 de la Ley 22/2009, tiene por objeto asegurar que cada Comunidad Autónoma recibe los mismos recursos por habitante ajustado para financiar los servicios públicos fundamentales esenciales del Estado de Bienestar. Es un mecanismo de garantía en el cual participan todas las Comunidades Autónomas con un porcentaje de sus recursos tributarios anteriormente definidos, en términos normativos, y el Estado con su aportación de recursos adicionales.
} 
En nuestra opinión, el principio de autonomía financiera, proclamado en los artículos 156 de la CE y 1 a 3 de la LOFCA, si bien se encuentra inevitablemente ligado al principio de autonomía política, ha de ser entendido como un instrumento indispensable en aras a la consecución efectiva de la autonomía política (STC de 30 de diciembre de 2000). Sin embargo no puede olvidarse, en contra de lo que manifiesta Villalta, la necesaria conexión de los citados principios con el principio de unidad, y es en este punto donde esta tesis no encuentra su fundamento legal. En su contra se encuentran los artículos 1.2; 9.1, 131.1; 138.2 y 139.2 de la CE. Asimismo pensamos que tal declaración de independencia contraria claramente el principio de igualdad de trato y no discriminación (arts. 139.1 y 149,1 CE)

Siguiendo esta línea argumentaría y en clara alusión a la cuestión soberanista reclamada por la Comunidad de Cataluña, cuya disconformidad con el actual sistema es más que evidente, su financiación se ve inmersa en otras cuestiones políticas que no le son favorables en el tratamiento otorgado a esta Comunidad por el legislador estatal. Si bien la Generalitat reconoce avances en el modelo de financiación como consecuencia de la aprobación de la reforma del EEAA, no se estiman suficientes ${ }^{7}$. Las actuales líneas reformistas reclaman la adopción de medidas concretas en aras a reducir el déficit fiscal y conseguir una financiación más equitativa que responda a las necesidades del pueblo de Cataluña y que permita desarrollar el autogobierno de forma plena. Asimismo, apuestan por el cumplimiento de compromisos plasmados en el texto estatutario como el principio de ordinalidad ${ }^{8}$ o las inversiones del Estado en Catalunya (disposición adicional tercera) ${ }^{9}$.

Y por si este panorama no fuera suficientemente desolador, la financiación de los territorios forales constituye otro debate que empieza a surgir en la sociedad española en relación con los principios constitucionales que afectan a la financiación autonómica; en clara referencia a los principios de igualdad en la aplicación de la ley, solidaridad y lealtad institucional. Y lo cierto es que nunca como hasta ahora se había

\footnotetext{
${ }^{7}$ La Ley Orgánica 6/2006, de 19 de julio, reforma el Estatuto de Autonomía de Cataluña y regula, en su título VI, la financiación de la Generalitat.

${ }^{8}$ El principio de ordinalidad, previsto en el art. 206.5 de la Ley Orgánica 6/2006, de 19 de julio, de reforma del Estatuto de autonomía de Cataluña, establece lo siguiente: "El Estado garantizará que la aplicación de los mecanismos de nivelación no altere en ningún caso la posición de Cataluña en la ordenación de rentas per cápita entre las Comunidades Autónomas antes de la nivelación”. La STC de 28 de junio de 2010 manifiesta que el artículo no es inconstitucional puesto que "ha de entenderse, en definitiva, como la manifestación expresa de un principio inherente al modelo de solidaridad interterritorial, en cuya virtud el Estado viene constitucionalmente obligado a procurar un "equilibrio económico, adecuado y justo” entre las Comunidades Autónomas que no perjudique a las más prósperas más allá de lo razonablemente necesario para el fin de la promoción de las menos favorecidas. De modo que la garantía del Estado a que se refiere este precepto sólo operaría cuando la alteración de la posición de la Comunidad Autónoma de Cataluña se debiera, no a la aplicación general de los mecanismos de nivelación, sino exclusivamente a la aportación que realizase Cataluña como consecuencia de su posible participación en dichos mecanismos. Con ese limitado alcance, así interpretado, el precepto no es contrario a la Constitución”. (FJ 134).

${ }^{9}$ Vid El informe sobre la financiación autonómica de Catalunya elaborado por el Consell de Treball, Econòmic $\mathrm{i}$ Social de junio de 2012. Disponible en http://www.ctesc.cat/estudis_i_informes/2012/index.html . Fecha de consulta 20/03/20167.
} 
planteado siquiera sugerir que los territorios forales gozaran de regímenes privilegiados en su financiación.

La Constitución realiza un claro reconocimiento de los derechos de los territorios históricos en la Disposición Adicional primera. Los estatutos de autonomía de Navarra (Ley Orgánica 13/1982, de 10 de agosto, de reintegración y amejoramiento del Régimen Foral de Navarra) y País Vasco (Ley Orgánica 3/1979, de 18 de diciembre, de Estatuto de Autonomía para el País Vasco) integran los derechos históricos y el reconocimiento de los fueros a estas CCAA. Los sistemas en los que se basa su modelo de financiación, Convenio y Concierto ${ }^{10}$ están siendo en la actualidad cuestionados por muchos $^{11}$.

Sobre el Concierto, De La Fuente (2012) establece diferencias con la ley foral: “... una cosa es el sistema foral per se, y otra muy distinta la forma específica en la que éste se ha aplicado, con resultados escandalosamente favorables para el País Vasco y Navarra”.

En cuanto al sistema foral per se, este autor piensa que no es un buen sistema ya que en él se observan anomalías puesto que no puede hallarse otro país en el que el gobierno central goce de la potestad de imponer tributos en una determinada área de su territorio (potestad que encuentra sus antecedentes en los derechos históricos reconocidos en el Antiguo Régimen). Asimismo, considera que las asimetrías creadas por el sistema respecto de otras CCAA contravienen claramente el principio constitucional de igualdad y además, los derechos reconocidos en la disposición adicional primera de la CE no justifican los privilegios en materia de financiación.

Por nuestra parte, nos mostramos totalmente de acuerdo con De La Fuente (2012) y entendemos siguiendo a López Laborda (2014), que uno de los mayores problemas que ocasiona la concesión de ciertos privilegios por el legislador a las Comunidades forales es la existencia de divergencias de nivelación con respecto al resto de CCAA; que se traducen en las diferencias de trato a los ciudadanos en el acceso a bienes y servicios públicos, contraviniendo claramente los principios de igualdad y de solidaridad. Ejemplos de lo anterior son las transferencias al Fondo de Garantía de Servicios Públicos. En este punto sería necesario reformar la Constitución con la inclusión del denominado principio de nivelación, que debe garantizar la efectiva aplicación del principio de igualdad en el acceso a los servicios públicos ofrecidos por las CCAA en aras a la consecución de un esfuerzo fiscal igualitario. De este modo, los territorios forales si tendrían la posibilidad de participar plenamente en el sistema propuesto, puesto que tal participación no es incompatible con los modelos de Concierto y Convenio.

\footnotetext{
${ }^{10}$ El Concierto es regulado en la actualidad en la Ley 12/2002, de 23 de mayo, por la que se aprueba el Concierto Económico con la Comunidad Autónoma del País Vasco y el Convenio encuentra su regulación en la Ley 28/1990, de 26 de diciembre, por la que se aprueba el Convenio Económico entre el Estado y la Comunidad Foral de Navarra.

${ }^{11}$ Vid un análisis de la problemática de los sistemas forales en materia hacendística desde el punto de vista constitucional en Reguera; Ruiz (2001) en Guerra (2001).
} 
Al respecto del Concierto, De Juan Peñalosa $(1979)^{12}$ se muestra muy crítico con el sistema por resultar, en su opinión, una fricción de la solidaridad interterritorial por dos motivos; el primero por la aplicación del principio del beneficio (según el cual la contribución de los ciudadanos al sector público se realizará en proporción a los servicios públicos recibidos) y el segundo por suponer una contribución negativa a los gastos generales que favorece a la desigualdad interregional.

Finalmente, en aras a finalizar esta revisión de la literatura, hemos de citar a Ferreiro (1997) ${ }^{13}$ quien concluye que las ventajas fiscales de las que goza la Comunidad del País Vasco no son determinantes ni para atraer inversiones de otras regiones ni para aumentar la actividad de su economía. Incluso se muestra contraria a la opinión generalizada de que esta CCAA realiza un "esfuerzo fiscal” superior al resto de CCAA si se utiliza en la medición de este factor (esfuerzo fiscal) un indicador objetivo como es el de la "presión fiscal para la imposición directa”.

Concluimos apostando por la imperiosa necesidad de la revisión de las bases en las que se fundamentan los modelo de Concierto y Convenio que, como no puede ser de otro modo, conlleva la modificación de las disposiciones adicionales primera y segunda de la LOFCA; así como la redacciones actuales de la Ley 12/2002, de 23 de mayo, por la que se aprueba el Concierto Económico con la Comunidad Autónoma del País Vasco y la Ley 28/1990, de 26 de diciembre, por la que se aprueba el Convenio Económico entre el Estado y la Comunidad Foral de Navarra.

\section{2- La financiación de la Comunidad Valenciana. Tendencias reformistas.}

Llegados a este punto y para referirnos a la financiación de la Comunidad Valenciana, consideramos necesario recordar como accedió esta CCAA a la autonomía en el proceso en que, tras la aprobación de 1978, se configuró el Estado autonómico.

En efecto, la Comunidad Valenciana no logra la autonomía por la vía de los llamados "territorios históricos" del artículo 151 de la CE; lo hace en virtud de lo dispuesto en el artículo 143.1. Lo verdaderamente destacable de este hecho es que consigue beneficiarse de las competencias plenas (de las que gozaron los territorios que reconoce la Constitución en el artículo 151) por medio de la aprobación de la Ley Orgánica 12/1982, de 10 de agosto, de transferencia a la Comunidad Valenciana de competencias en materia de titularidad estatal (LOTRAVA). La citada disposición normativa, en su artículo primero, configura al artículo 152.2 de la CE como el instrumento capaz de transferir todas aquellas competencias correspondientes a materias de titularidad estatal comprendidas en el Estatuto de autonomía, que excedan de las competencias configuradas en el artículo 148 de la CE.

Carrasco Canals (1989) estableciendo semejanzas y divergencias entre la citada norma y la Ley 11/1982, de 190 de agosto (LOTRACA), que curiosamente se aprueba

\footnotetext{
12 Citado por La Cruz Rodríguez (2000).

${ }^{13}$ Hemos de matizar que el estudio realizado por esta autora se efectúa con los patrones establecidos por el modelo de financiación autonómica de 2001; en aras a alcanzar conclusiones coherentes, debería efectuarse el mismo o similar análisis respecto del vigente modelo de financiación con base en datos actuales.
} 
el mismo día y que hizo efectivo el traspaso de competencias a la Comunidad de Canarias, halla semejanzas en sus estructuras; ambas son muy breves y su contenido es análogo, sin embargo se observan notables diferencias en cuanto a su justificación y plazo en relación con el Estatuto de Autonomía.

Mainar Cabanes (2010) califica el proceso de autonomía valenciano de “desencuentro y desencanto social” en el que afloraron problemas de difícil solución; discrepancias en torno a la bandera y otros aspectos, que aun después de varias décadas subsisten y permanecen sin resolver en buena parte de la sociedad.

Hoy en día, con una autonomía totalmente consolidada y un Estatuto reformado en 2006 (por Ley Orgánica 1/2006, de 10 de abril) parece claro que la Comunidad Valenciana no goza de privilegios en lo relativo a su financiación, más bien lo contrario $^{14}$.

Antes de entrar de lleno en el análisis de la situación actual de la financiación valenciana y con el fin de corroborar la anterior afirmación es conveniente precisar sus principales fuentes de ingresos: recursos procedentes de la participación en los ingresos estatales, ingresos de carácter tributario (tributos cedidos por la Administración General del Estado y tributos propios); subvenciones procedentes estatales y de la Unión Europea; y por último otros ingresos, de naturaleza un tanto heterogénea y cuya cuantía no es especialmente relevante. Asimismo, esta CCAA, al igual que el resto, obtiene financiación a través de operaciones de crédito y emisiones de deuda pública de la Generalitat. Los datos presentados corresponden a los ejercicios presupuestados 2015, 2016 y 2017 (unidad: millones de euros) ${ }^{15}$.

En lo relativo a los ingresos no financieros se encuentran los siguientes conceptos: tasas y precios públicos, subvenciones de otras Administraciones (excepto fondos europeos), fondos europeos y resto de ingresos; tributos cedidos gestionados por el Estado, tributos cedidos de gestión propia, tributos propios de la Generalitat: la evolución de estos ingresos ha pasado de 12.154,01 en 2015, 13.005,42 en 2016 y 13.586,14 en 2017. Puede observarse su evolución al alza.

En cuanto a la participación en ingresos del Estado, las transferencias del Estado constituyen la principal fuente de financiación (80\% del total de los ingresos). La participación de las Comunidades Autónomas en ingresos estatales, incluyendo las partidas de los impuestos sobre la renta (IRPF) y sobre el valor añadido (IVA), así como otros impuestos especiales (como los impuestos sobre el alcohol, el tabaco o la electricidad): las cifras son 7.624,63 en 2015, 7.953,24 en 2016 y 8.230,75 en 2017.

\footnotetext{
${ }^{14}$ A lo anterior hemos de añadir que las Cortes Valencianas plantean ante el Congreso de los Diputados la Propuesta de reforma de la disposición adicional primera del Estatuto de Autonomía de la Comunidad Valenciana en la redacción dada por la Ley Orgánica 1/2006, de 10 de abril. Dicha reforma se aprueba por el pleno del Congreso el 9 de septiembre de 2016. La redacción de la citada disposición es la siguiente: “1. La inversión del Estado en la Comunitat Valenciana, excluido el Fondo de Compensación Interterritorial, será equivalente al peso de la población de la Comunitat Valenciana sobre el conjunto del Estado por un periodo de siete años. 2. Con esta finalidad se constituirá una comisión integrada por la administración estatal y autonómica."

15 Información extraída íntegramente del Portal del Transparencia de Generalitat Valenciana: http://www.gvaoberta.gva.es/financiacion. Fuente: Conselleria de Hacienda y Modelo Económico. Dirección General de Presupuestos. Fecha de consulta 22/03/2017.
} 
Como complemento a lo anterior, existen los siguientes fondos:

- El Fondo de Garantía de Servicios Públicos Fundamentales, que debe garantizar un nivel homogéneo en todo el territorio nacional en lo relativo a la prestación de los servicios públicos de educación, sanidad y servicios sociales esenciales.

- El Fondo de Suficiencia Global, encargado de determinar la diferencia entre las necesidades de gasto de la comunidad autónoma y la suma de su capacidad tributaria y la transferencia del Fondo de Garantía de Servicios Públicos Fundamentales anterior. Destacamos que es negativo durante los tres ejercicios referidos: -1.499,83 en 2015, - 1.395,72 en 2016 y 1.269,99 en 2017.

- Los Fondos de Convergencia Autonómica (el Fondo de Competitividad y el Fondo de Cooperación) destinados a aproximar las Comunidades Autónomas en términos de financiación por habitante ajustado y de favorecer el equilibrio económico territorial presentan un valor de 0 .

En cuanto a los ingresos por tributos cedidos por el Estado, entre los que se encuentran las siguientes figuras impositivas: el impuesto sobre transmisiones patrimoniales y actos Jurídicos documentados; el impuesto sobre sucesiones y donaciones y el impuesto sobre el patrimonio; las tasas y precios públicos; y otros ingresos de naturaleza tributaria. Los citados ingresos evolucionan del siguiente modo: 2.046,66 en 2015, 1.873,98 en 2016 y 1.968,99 en 2017. En este punto se observa una disminución con respecto a años anteriores. Si efectuamos un desglose, puede apreciarse una notable disminución de los ingresos procedentes de la tasa fiscal sobre el suelo (186,68 en 2015; 163,05 en 2016 y 137,07 en 2017) así en los ingresos procedentes de otras tasas afectas a los servicios (484,58 en 2015, 367,72 en 2016 y 348,13 en 2017) y en otros ingresos de naturaleza tributaria (47,22 en 2015 , 42,92 en 2016 y 31,13 en 2017).

El total de recursos del sistema de financiación es el resultado de la suma de los ingresos obtenidos por la participación en los ingresos del Estado con los ingresos tributarios por tributos cedidos: 9.671,29 en 2015, 9.827,22 en 2016 y 10.236,49 en 2017).

En el apartado relativo a los impuestos propios se encuentran en la actualidad el impuesto sobre los depósitos en las entidades de crédito, el impuesto autonómico sobre el juego y los impuestos medioambientales; en este apartado se observan datos positivos: 55,95 en 2015, 71,38 en 2016 y 70,96 en 2017; sin embargo el peso de estos tributos respecto del total de ingresos tributarios muy poco significativo.

En lo relativo a las subvenciones de otras administraciones públicas y fondos europeos, se incluyen los siguientes conceptos: transferencias tanto corrientes de capital, recibidas por la Generalitat, del Estado, de la Seguridad Social, de las corporaciones locales y del exterior (fondos europeos). Los datos obtenidos son los siguientes: 2.072,74 en 2015, 3.954,04 en 2016 y 2.888,55 en 2017. 
Finalmente, en lo referente al resto de ingresos, procedentes de reintegros, ingresos patrimoniales, enajenaciones, los datos son: 257,43 en 2015, 50,67 en 2016 y 15,64 en 2017.

Asimismo y en otro orden de cosas, adquieren importancia las conclusiones expuestas por el informe sobre el grado de cumplimiento del objetivo de estabilidad presupuestaria, de deuda pública y de la regla de gasto del ejercicio 2015 (objetivo en aras a garantizar la sostenibilidad financiera de todas las Administraciones Publicas) establecido en la Ley Orgánica 2/2012, de 27 de abril, de Estabilidad Presupuestaria y Sostenibilidad Financiera (LOEPSF): la Comunidad Valenciana registra cifras de déficit superiores al objetivo fijado por el Gobierno en Consejo de Ministros ${ }^{16}$.

Hemos de añadir, que la Autoridad Independiente de Responsabilidad Fiscal en su informe sobre las Previsiones Macroeconómicas de 23 de enero de 2017 no es optimista ni en el caso del PIB ni en el empleo en su análisis efectuado a la Comunidad Valenciana; aun así, las previsiones son prudentes al igual que para Andalucía, Canarias, Galicia y Navarra.

Con base en lo anterior, evidentemente concluimos que el modelo de financiación estatal no está arrojando los resultados deseados para la Comunidad Valenciana y urge su revisión; ya en el año 2013, un Comité de Expertos del Alto Consejo Consultivo de la Comunidad Valenciana (Comisión de Economía) formado por profesores universitarios, redactó una propuesta de bases para un nuevo sistema de financiación autonómico. Sus críticas al actual modelo de financiación son las siguientes:

- Es “complejo y oscuro"; se basa en la presunción de que las CCAA (sin tener en cuenta sus estimadas necesidades) no pueden ver disminuidos sus recursos en relación con el sistema anterior, sin embargo no se plantea más.

- Potencia desigualdades, ocasionando un reparto arbitrario de recursos entre regiones; casi 50 puntos de diferencia entre las CCAA que resultan mas beneficiadas y las menos favorecidas

- Los tributos propios, que ocasionan múltiples controversias, son recursos a los que las CCAA acuden con mayor frecuencia de la que es aconsejable. Esta proliferación no resulta en absoluto beneficiosa

- La responsabilidad financiero-fiscal de las CCAA, a causa de la crisis económica ha fracasado.

- Se observan importantes deficiencias en el diseño del modelo de financiación; evidencias de ello es la diversidad de ingresos existente entre el momento del traspaso de las competencias y el ulterior endeudamiento.

\footnotetext{
${ }^{16}$ Las CCAA que cumplen el objetivo de déficit son Galicia, País Vasco y Canarias. Al igual que la Comunidad Valenciana no cumplen el objetivo Andalucía, Aragón, Asturias, Baleares, Castilla y León, Castilla La Mancha, Cataluña, Cantabria, Murcia, Extremadura, Madrid, Navarra y La Rioja. Vid informe disponible mpleto\%20EP\%202015\%20(1).pdf. Fecha de consulta 22/03/2017.
} 
- La ordenación de las CCAA, con base en una clasificación en virtud de los recursos obtenidos tras la aplicación del sistema, carece de toda lógica.

En consecuencia, el modelo de financiación propuesto por el citado Comité se fundamenta en los siguientes aspectos:

1. Los pilares del sistema se sostienen en el principio de igualdad de los ciudadanos, independientemente del lugar de residencia

2. Los ingresos podrían ser similares a los que contempla el sistema actual; el Gobierno debe asegurar su capacidad de satisfacer, en condiciones de coste real objetivo y con el mayor grado de eficiencia, el coste estándar derivado de aquellas competencias, exclusivas de las CCAA o cedidas, que son propias de cada CCAA

3. En el gasto sanitario la variable de población ajustada ha entenderse como variable de reparto esencial.

4. Se apuesta por un único fondo de nivelación horizontal, con criterios de reparto “objetivos y razonables”; lo que supondría situar la financiación per cápita muy cercana a la media de la establecida para el conjunto de transferencias adicionales.

Por otra parte, al informe anterior se le suma el elaborado en 2013 por otro Comité de Expertos nombrado por las Cortes Valencianas( ya citado en la introducción de este trabajo): "Criterios y propuestas para un nuevo sistema de financiación autonómica” y sus conclusiones son las que siguen:

- Necesidad del incremento del espacio fiscal propio, así como del grado de corresponsabilidad fiscal en la gestión tributaria.

- El sistema de financiación ha de ser capaz de solventar las elevadas “asimetrías" existentes entre CCAA, en lo relativo a la financiación por habitantes.

- Debe otorgarse un trato diferenciado en la financiación de los servicios públicos fundamentales (seguridad, orden público, sanidad, educación y protección social) no solo a nivel autonómico sino también a nivel estatal.

- Instauración de una nueva visión para la financiación del conjunto de las Administraciones públicas valencianas, fruto del consenso; dimensión financiera de las CCAA y sus principales funciones.

- Supresión de los fondos fijados por anteriores modelos y establecimientos de mejoras y compromisos efectivos y firmes, en lo que al suministro de información se refiere.

- Necesidad de establecimiento de una serie instrumentos complementarios: instrumentos de desarrollo regional; de reequilibrio financiero y contribuciones forales a las cargas generales del Estado, capaces de mejorar los resultados del sistema. 
Ya en fechas más recientes, septiembre de 2016, ve la luz el informe para la reforma del sistema tributario valenciano en el que se presentan propuestas para el siguiente ejercicio presupuestario (2017). Se pretende el diseño de un sistema tributario valenciano incluido de manera adecuada en el nuevo sistema de financiación de las Comunidades Autónomas para el conjunto de todas ellas. ${ }^{17}$

No podemos dejar de mencionar en el marco de esta línea reformista, el manifiesto por una financiación justa para la Comunidad Valenciana. Impulsado por la Generalitat Valenciana en septiembre de 2016 y apoyado por sectores de tendencia claramente progresista de la sociedad valenciana. El documento clama por una reforma inmediata del sistema de financiación; el reconocimiento de los déficits de financiación acumulados desde la ejecución de las transferencias de competencias a la Comunidad Valenciana (cifrada en al menos 12.433 millones de euros desde 2002 a 2013): Asimismo aboga por la definición y el establecimiento de un mecanismo de compensación de dichos déficit y de la ejecución estatal de inversiones en infraestructuras equiparables; como mínimo, al peso de la población de la Comunidad Valencia, capaz de compensar la insuficiencia en inversiones en los últimos años.

Asimismo nos hacemos eco de la Proposición de Ley presentada por el Grupo parlamentario Compromís ante las Cortes Valencianas (1 de julio de 2016, REF número 25.747) en la que se solicita que el actual artículo 135 de la CE vuelva a su redacción originaria, anterior a la reforma de este precepto de 2011; la justificación de esta iniciativa se encuentra en el perjuicio que produciría, según este grupo parlamentario, la limitación del déficit. Podría ocasionar el empeoramiento del bienestar de los ciudadanos en lo referente a las políticas de recuperación social, que se están llevando acabo con motivo de la crisis económica.

Por nuestra parte, aportamos algunas propuestas, entre las que incluimos algunas de "lege ferenda" que podrían contribuir a paliar en buena medida la difícil situación por la que atraviesa la Comunidad Valenciana; en primer lugar, es evidente que un incremento de la corresponsabilidad fiscal no es aconsejable a través de la vía del establecimiento de tributos propios, debido a su bajo potencial recaudatorio. Sin embargo, pensamos que figuras impositivas como el impuesto sobre estancias de establecimientos turísticos (establecido en la Comunidad de Cataluña) con claro carácter parafiscal, serian capaces de incrementar los ingresos de la Comunidad, debido a la actual importancia del sector turístico en la misma ${ }^{18}$.

Asimismo, consideramos que seria más prudente incrementar la corresponsabilidad fiscal mediante el aumento de los porcentajes de cesión de los tributos estatales; concretamente para el caso del IRPF. El instrumento adecuado para la consecución de ese objetivo son las leyes de cesión de tributos del Estado: así, debería

17

http://www.hisenda.gva.es/documents/90598172/163676496/Comisi\%C3\%B3n+Expertos+Informe+final +30+septiembre.pdf/7a674901-fd12-4c02-8ba1-b6fd6c27b377. Fecha de consulta 22/03/2017.

${ }^{18}$ La recaudación de dicho tributo en la Comunidad de Cataluña en 2015 sube un 5,5\% respecto a 2014; el total recaudado desde 2012 supera los 126 millones de euros. Fuente: https://www.google.es/\#q=generalitat+de+catalunya. Fecha de consulta: 10/07/2017. 
modificarse la redacción actual del artículo primero que establece un porcentaje de cesión del 50 por ciento y fijarse un porcentaje máximo del 60 porciento.

En cuanto a la regulación que de esta materia se contiene en el Estatuto de autonomía valenciano, seria conveniente una mayor concreción en su articulado en aras a incrementar la seguridad jurídica; así, abogamos por la inclusión en el artículo 67. 1, cuya redacción actual es "La financiación de la Generalitat se basa en los principios de autonomía, suficiencia y solidaridad”, de los principios de lealtad institucional, igualdad y equidad en el gasto público. Asimismo, se hace necesario especificar y concretar las medidas de compensación a las que hace mención el artículo 68 del citado texto.

Somos de la opinión de que la modificación de la LOFCA es esencial, sobre todo en aquellos aspectos relativos a la supresión y/o simplificación de la multitud de fondos existentes en la actualidad y regulados en los artículos 13 y siguientes. Además de las propuestas formuladas por los distintos Comités, la citada norma debería incluir la obligatoriedad de reuniones periódicas del Consejo de Política Fiscal y Financiera (constituido en virtud del articulo 3).

Finalmente y en aras a asegurar la efectiva aplicación del principio de igualdad de los ciudadanos, independientemente del lugar de residencia (propuesto por el Comité de Expertos del Alto Consejo Consultivo) y de acuerdo con el articulo 19 de la CE, podría estipularse la aprobación de un paquete de medidas consistentes en la concesión de beneficios fiscales a las personas físicas que realicen actividades económicas y trasladen su residencia a la Comunidad Valenciana; el cauce para su adopción es su inclusión en la Ley 21/2001, de 27 de diciembre, por la que se regulan las medidas fiscales y administrativas del nuevo sistema de financiación de las Comunidades Autónomas de régimen común. No obstante y pese a que la citada disposición normativa establece en su articulo 38.2 el limite de las deducciones de la cuota establecidas y reguladas por la normativa del Estado, entendemos que en ningún caso las medidas que proponemos vulneran el limite establecido (Vid articulo 68.2 de la Ley 35/2006, de 28 de noviembre, del Impuesto sobre la Renta de las Personas Físicas). Estas medidas son pueden ser igualmente aplicables a personas jurídicas.

\section{LA SOSTENIBILIDAD DEL GASTO SANITARIO. PROBLEMAS ACTUALES.}

Inmersos ya en la perspectiva de los gastos, el gasto sanitario es y ha sido en la última década, uno de los mayores quebraderos de cabeza tanto para las CCAA como para el Estado. La cláusula constitucional que permite el traspaso de las competencias en materia de sanidad e higiene se halla en artículo $148,1,21^{\mathrm{a}}$. Como ya dijimos en anteriores trabajos, Lópaz Pérez (2014), la descentralización del gasto sanitario no fue similar, en lo concerniente a su aplicación, en todas las CCAA.

López Casanovas (2016) apunta que debe entenderse por descentralización del gasto sanitario al proceso por el cual se llevan a cabo la transferencia de plenas competencias, en un escenario en el que las Entidades Locales obtienen claramente una ventaja comparativa. Asimismo califica al proceso de "proceso estrella" y lo considera factor determinante en los resultados obtenidos por el Estado autonómico. 
El Gobierno estatal ha estado siempre preocupado por el gasto público sanitario, constante objeto de atención en las Conferencias de Presidentes autonómicos; tanto es así que del seno de la Conferencia celebrada en 2004 surge la creación del Grupo de Trabajo para el análisis del gasto sanitario. Del informe emitido por el Grupo en $2005^{19}$ se desprende una urgente necesidad de racionalización y por ende de incrementar su sostenibilidad; mandato dirigido tanto los responsables de las políticas sanitarias como a los usuarios de los servicios. El Grupo emite otro informe en $2007^{20}$ que arroja los siguientes datos:

La tasa de crecimiento medio anual del gasto sanitario público total en España en el periodo de 1999 a 2005 se sitúa en el 8,53 por ciento. El volumen de gasto en alcanza los 50.053 millones de euros en 2005. Sin embargo, en los ejercicios 2004 y 2005 la tasa de crecimiento interanual del gasto total $(8,10$ y 8,38 por ciento, respectivamente) se modera comparándola con la correspondiente a 2003 que fue un 11,37 por ciento.

Murcia, Baleares, La Rioja, Comunidad Valenciana, Castilla-La Mancha, Canarias, Cantabria, Melilla y Aragón son las Comunidades y Ciudades Autónomas con gasto sanitario público creciendo por encima de la media. Por debajo se hallan Galicia, Navarra y Ceuta y País Vasco, al igual que ocurrida en el periodo 1999-2003. Extremadura y Catalunya (que entre 1999 y 2003 crecía por encima de la media) y Madrid (que crecía por debajo) aumentan como la media entre 1999 y 2005 aproximadamente.

Por lo que a la Comunidad Valenciana concierne, el problema del gasto sanitario se pone de manifiesto en todos los informes emitidos por comités de expertos sobre la reforma del sistema de financiación. Así, el Comité de Expertos del Alto Consejo Consultivo de la Comunidad Valenciana de 2013 observa un incremento al alza en el gasto sanitario del 69 por ciento, estimándose en un 15 por ciento el aumento de la población (2002-2010). La conclusiones son un aumento del coste sanitario, y consecuentemente del gasto por habitante, como consecuencia del incremento de la población.

Por su parte, el informe del Comité de Expertos nombrado por las Cortes Valencianas incorpora en sus conclusiones finales la propuesta del Tramo de Garantía del nivel mínimo de los servicios fundamentales (SPF) cuyas principales características son:

- Determinación de la dimensión del gasto (SPF) mediante el instrumento del acuerdo en el Parlamento.

\footnotetext{
${ }^{19}$ Vid Informe para el análisis del gasto sanitario. Grupo de Trabajo de la Conferencia de Presidentes para el análisis del gasto sanitario presidido por la IGAE. Julio de 2005. Publicaciones Instituto de Estudios Fiscales (IEF). Disponible en: http://www.ief.es/documentos/recursos/publicaciones/libros/Libros blancos/GastoSanitario.pdf. Fecha de consulta: 23/03/2017. Vid alegaciones de la Comunidad Valenciana al informe en LÓPAZ (2014).

20 Informe del Grupo de trabajo sobre el gasto sanitario 2007. Disponible en: http://www.minhafp.gob.es/Documentacion/Publico/PortalVarios/Grupo\%20de\%20Trabajo\%20Gasto\%2 0Sanitario.pdf. Fecha de consulta: 23/03/2017.
} 
- Establecimiento de la asignación a los SPF del porcentaje que se estime conveniente de la recaudación de las principales figuras impositivas del sistema tributario (IVA, Especiales y las cotizaciones sociales e IRPF).

- Constitución de un fondo de reserva de los SPF, complemento a la financiación de los gastos anteriores.

En aras a paliar la situación de la financiación de la sanidad, la Comunidad Valenciana contaba con el "céntimo sanitario" (la Ley 11/2005, de 9 de diciembre, de la Generalitat Valenciana), consistente en la imposición de tipos de gravamen autonómicos en el Impuesto sobre las Ventas Minoristas de Determinados Hidrocarburos (IVMDH). La citada medida impositiva pretendía resolver el problema que para esta CCAA implica la existencia de un importante volumen de población turística flotante; por el envejecimiento general de la población -unido, en determinadas zonas, a la importancia del turismo residente de la tercera edad-; y por ser uno de los principales polos españoles de atracción de inmigrantes -a veces en situación irregular o no contributiva, pero cubiertos igualmente por el sistema público de salud ${ }^{21}$. El IVMDH estuvo en vigor en España entre el 1 de enero de 2002 y el 1 de enero de 2013; fecha en la que se produjo su integración en el Impuesto Especial sobre los Hidrocarburos ${ }^{22}$.

La sentencia del Tribunal de Justicia de las Comunidades Europeas (TJCE) de 27 de febrero de 2014 (asunto C-82/12) declara contrario a la normativa comunitaria el "céntimo sanitario" aplicado a los carburantes. La citada resolución resuelve una petición de decisión prejudicial planteada, con arreglo al artículo 267 TFUE, por el Tribunal Superior de Justicia de Cataluña, mediante auto de 29 de noviembre de 2011, recibido en el Tribunal de Justicia el 16 de febrero de 2012, en el procedimiento entre Transportes Jordi Besora, S.L., y la Generalitat de Catalunya. El TJCE esgrime, entre otras razones, que la medida impositiva en su aplicación contraviene la Directiva sobre los impuestos especiales.

Llegados a este punto y es obligada la referencia a una de la formas más extendidas de prestación de los servicios públicos sanitarios en la Comunidad Valenciana: el concierto. Y nos referimos a esta modalidad de gestión indirecta

\footnotetext{
${ }^{21}$ Ley 6/2008, de 2 de junio, de la Generalitat, de Aseguramiento Sanitario del Sistema Sanitario Público de la Comunitat Valenciana pretendió ofrecer una respuesta al modelo de financiación estatal, incapaz de adaptarse al incremento de la población que en el territorio de la Comunidad Valenciana es mayor que la media nacional. La norma obligaba a registrar la asistencia prestada a las personas desplazadas temporalmente que procedan de otra Comunidad Autónoma o del extranjero. Esta norma se encuentra derogada tras la aprobación de Ley 10/2014, de 29 de diciembre, de Salud de la Comunitat Valenciana (disposición derogatoria única).

${ }^{22}$ Ya el Dictamen de la Comisión Europea motivado, de 6 de mayo de 2008, advierte a España que el Impuesto Especial sobre las Ventas Minoristas de determinados Hidrocarburos podría constituir motivo de infracción de la normativa comunitaria, por considerar que la recaudación del citado impuesto no se ajusta a la del Impuesto Especial sobre Hidrocarburos; recaudación armonizada en toda la Unión Europea. Asimismo, esta institución comunitaria entiende que la finalidad del tributo es meramente presupuestaria; claramente contraria a la Directiva 92/12/CEE, y con el objetivo final de incrementar los ingresos tributarios de las Comunidades Autónomas. La Comisión se muestra firme al exigir a España su modificación en el plazo de dos meses. En caso contrario, la Comisión remitirá el asunto al Tribunal de Justicia de Luxemburgo.
} 
preguntandonos si su actual modelo es capaz de contribuir a la sostenibilidad del gasto sanitario.

La Ley 3/2003, de 6 de febrero, de la Generalitat, de Ordenación Sanitaria instituye el concierto sanitario y supone el punto de partida para su generalización en toda la Comunidad Valenciana ${ }^{23}$. La norma, en la actualidad derogada por la Ley 10/2014, permite la gestión de hospitales como el de Alzira (constituido en 1999 amparado por la Ley 15/1997 y el Real Decreto 29/2000, de 14 de enero) con un singular modelo cuyos rasgos esenciales son la propiedad pública, control público, financiación pública y gestión privada ${ }^{24}$. La concesión de dicha forma de gestión fue motivo de posterior impugnación ante el Tribunal Superior de Justicia (TSJ) de la Comunidad Valenciana. El TSJ valenciano desestimó el recurso, que fue interpuesto por la confederación sindical Comisiones Obreras, en la sentencia 1925/2000, de 20 de diciembre (JUR 2001/160009), aduciendo que no existen razones legales a su prohibición.

Al hospital de Alzira le siguieron los hospitales de Torrevieja (año 2006), Denia (año 2009), Manises (año 2009) y Elx-Crevillente ( año 2010). Blasco, R. el que fue Conseller de Sanidad a la fecha de constitución del hospital de Alzira, califica el modelo como mixto de colaboración. Se pretendía la atención universal de la sanidad, eliminado los defectos observados en los modelos públicos y privados. El fin es una atención de calidad por medio del establecimiento de cláusulas que debe cumplir el gestor en aras a asegurar la atención ciudadana y hacer efectivo el principio de cercanía de los servicios sanitarios.

Hemos de destacar que la Ley 10/2014, de 29 de diciembre, de Salud de la Comunitat Valenciana introduce como principios rectores (art. 4) la descentralización, desconcentración, autonomía, coordinación institucional y responsabilidad en la gestión de los servicios y programas de salud e inicia un proceso que pretende la regulación eficaz y transparente del sistema de conciertos. La aprobación en las Cortes Valencianas la de Ley 7/2017, de 30 de marzo, de la Generalitat, sobre acción concertada para la prestación de servicios a las personas en el ámbito sanitario, representa un significativo avance en el citado proceso y no se encuentra exenta de polémica; la norma aspira a la transparencia y se ciñe, en el marco de la reciente jurisprudencia del Tribunal de Justicia de la Unión Europea, a la prestación de los servicios por entidades sin ánimo de lucro (art. 5.1); es decir, solo tendrán acceso al régimen del concierto las entidades públicas o privadas sin ánimo de lucro prestadoras de servicios sanitarios previamente autorizadas por la administración. Lo que se trata de evitar es que entidades privadas se lucren y obtengan beneficios, por lo que su retribución se limitará al reintegro de costes en el marco del principio de eficiencia presupuestaria.

\footnotetext{
${ }^{23}$ El articulo 23 de la norma establecía: "La gestión y administración de los centros, servicios y establecimientos sanitarios de protección de la salud o de atención sanitaria o sociosanitaria podrá llevarse a cabo directamente o indirectamente, con medios propios o ajenos, públicos o privados, mediante cualesquiera entidades admitidas en derecho, así como a través de la constitución de concesiones administrativas, consorcios, fundaciones, empresas públicas u otros entes dotados de personalidad jurídica propia, pudiéndose establecer, además, acuerdos o convenios con personas o entidades públicas o privadas y fórmulas de gestión integrada o compartida”.

${ }^{24}$ Vid Calero Martina; Gallarza (2010).
} 
En nuestro país el sistema de conciertos sanitarios se halla muy extendido. En la Comunidad de Madrid, en contra del proceso aunque sin manifestarse a favor de su total prohibición, se muestra el auto del Tribunal Superior de Justicia (TSJ) 1/2014, de 27 de enero. En esta resolución el tribunal acuerda el mantenimiento de la medida cautelar de suspensión de la externalización sanitaria y rechaza el recurso de reposición interpuesto por la Comunidad de Madrid y las empresas adjudicatarias de las concesiones.

$\mathrm{Al}$ respecto de la conveniencia o no de la fórmula del concierto hemos de citar opiniones a favor y en contra. Arenas Díaz (2013) expone que la media del gasto invertido en sanidad (atención primaria y especializada) referente a los Departamentos de Salud en concesiones de gestión privada durante el año 2012 es ligeramente inferior a la de los Departamentos de gestión publica directa (en términos brutos se estima en un 226 por ciento). Tal divergencia es menor cuando los tipos de Departamentos que comparan se hacen homogéneos (el 11,7 por ciento si se calcula sin los Departamentos outsiders), Departamentos con Hospitales de tercer nivel y los de escasa población. Algunos departamentos de gestión publica presentan un gasto per cápita significativamente inferior que el de los conciertos (dos de diecinueve).

Menéndez Rexach (2008) se pregunta si seria viable una seguridad social en la que la asistencia sanitaria fuera prestada en su mayor parte por establecimientos privados; la respuesta, acertadísima en nuestra opinión, sería afirmativa solo en el sentido en el que el Estado ejerciera un papel de garante "regulador", no de prestador de servicios.

Considerando el tipo de entidades que deben ser las prestadoras de los servicios, Cataluña y Baleares recogen en su propia normativa la fórmula del concierto con entidades sin ánimo de lucro, si bien no de forma exclusiva; se muestran claramente permisivos, reconociendo prioridad frente al resto de entidades privadas. Otras comunidades, como el caso de la Valenciana, blindan el concierto a entidades del llamado "tercer sector" con tarifas revisables periódicamente, que retribuirán como máximo los costes variables, fijos y permanentes de las prestaciones garantizando la indemnidad patrimonial de la entidad prestadora, sin incluir beneficio industrial (art 5.1, Ley 7/2017).

Y precisamente, a favor del concierto por entidades del "tercer sector" se muestra la normativa comunitaria. La Directiva 2014/24/UE, en el marco de las previsiones del Tratado de Funcionamiento de la Unión Europea, establece que la aplicación de la normativa contractual pública no es la única opción de que disponen las autoridades en aras a gestionar los servicios a las personas. Por otra parte, el Tratado de Funcionamiento de la Unión Europea se muestra a favor de la capacidad de organización de la prestación de servicios no económicos de interés general a las personas. En esta misma línea argumentaría se halla la normativa comunitaria más reciente sobre contratación, y la sentencia del Tribunal de Justicia de la Unión Europea de 28 de enero de 2016 (asunto C-50/14). En la citada resolución judicial se admite la colaboración con entidades sin ánimo de lucro autorizada, por la legislación de los estados miembros, como instrumento para la consecución de los objetivos de solidaridad y de eficiencia presupuestaria, si bien mediante el control de los costes de los servicios a las personas siempre que estas entidades "no obtengan ningún beneficio 
de sus prestaciones, independientemente del reembolso de los costes variables, fijos y permanentes necesarios para prestarlas, ni proporcionen ningún beneficio a sus miembros".

Por nuestra parte, nos mostramos partidarios del concierto con entidades privadas sin ánimo de lucro, pero en ningún caso en exclusiva. La razón de esta idea se basa en que la no obtención de beneficios puede suponer la correlativa reducción de costes y como consecuencia una preocupante disminución en el nivel de calidad y atención a los usuarios. Por ello, entendemos que podrían tener cabida entidades con y sin ánimo de lucro y aquellas otras que forman parte de la entidades de la economía social; las cooperativas.

En efecto, las cooperativas son las entidades, en sus orígenes sin ánimo de lucro, que pueden prestar los servicios sanitarios de manera efectiva. El modelo cooperativo se fundamenta en los principios proclamados por la Alianza Cooperativa internacional y entre otros destacan la democracia, la solidaridad, la igualdad y vocación social. Las sociedades cooperativas se caracterizan por su capacidad de adaptación a los cambios sociales y laborales, especialmente a los producidos como consecuencia de la crisis económica de los últimos años; además puede afirmarse que presentan una resistencia mayor a la destrucción de empleo, frente al resto de entidades privadas.

En materia de educación, tanto en la Comunidad Valenciana como en el resto de CCAA, las cooperativas son entidades a las que se les permite prestar servicios en forma de concierto. El Decreto 6/2017, de 20 de enero, del Consell, por el que se aprueba el Reglamento de conciertos educativos en la Comunitat Valenciana no prohíbe este hecho y, al igual que la Ley 7/2017 fundamenta en la Directiva 2014/23/UE, del Parlamento Europeo y del Consejo de 26 de febrero de 2014 (directamente aplicable desde el 18 de abril de 2016) la necesidad de garantizar la observancia de los principios de transparencia e igualdad de trato en la adjudicación de contratos en el ámbito de los servicios educativos. El Real Decreto 2377/1985, de 18 de diciembre, por el que se aprueba el Reglamento de normas básicas sobre conciertos educativos, es el marco de normativo al que se someten los centros privados. Si el modelo cooperativo participa activamente del concierto educativo, no encontramos razón por la que no pueda prestar servicios sanitarios o sociales y participar así del concierto sanitario. Tampoco existe en la Ley 27/1999, de 16 de julio, de Cooperativas ninguna razón de oposición al mismo.

Para concluir, y en virtud de la posibilidad de la calificación de una cooperativa como entidad sin ánimo de lucro recogida por la disposición adicional primera de la Ley 27/99, proponemos una fórmula mixta que si tendría cabida en la Ley 7/2017 y siempre que gestione servicios de interés colectivo o de titularidad pública; la prestación de los servicios sanitarios concertados por una cooperativa calificada sin animo de lucro. No obstante, es importante señalar que la cooperativa ha de respetar una serie de limitaciones: la prohibición de distribución de resultados positivos a sus socios; la prohibición de devengar un interés superior al legal del dinero por parte de las aportaciones de los socios al capital social (obligatorias y voluntarias), sin perjuicio de la posible actualización de las mismas y la gratuidad de los cargos de los miembros del consejo rector. 
Finalmente, y siguiendo a Sánchez Bayle (2014) en su propuesta de fórmulas alternativas a la privatización de la sanidad en aras a garantizar la sostenibilidad del gasto sanitario, podría considerarse lo siguiente:

- Incremento del porcentaje de presupuesto público destinado a la Sanidad y mediante la elaboración de un Plan Integrado de Salud y el establecimiento de sistemas de información homogéneos en aras a lograr un sistema garante de la suficiencia financiera del Sistema Nacional de Salud.

- Control del gasto farmacéutico potenciando el consumo de medicamentos genéricos para alcanzar el 25 por ciento del gasto farmacéutico.

- Establecimiento y posterior puesta en funcionamiento de protocolos de utilización de tecnología, redactados evidencias científicas en uso.

- Constitución de la Agencia central de compras del SNS, sistema basado en economías de escala.

- Paralización de las privatizaciones, estimación y valoración de sus resultados y posterior inclusión en sistema sanitario pública.

- Protección y salvaguardia de la Atención Primaria por medio de profesionales comprometidos y materiales de calidad y la facilitación del acceso por los ciudadanos a pruebas diagnósticas.

- Revisión y mejora de las relaciones y la coordinación entre la atención especializada y la atención primaria y fomento de las vías de participación de profesionales y usuarios.

\section{A MODO DE CONCLUSIÓN}

En el presente apartado, procedemos a exponer las conclusiones de nuestro trabajo con la pretensión de resaltar los aspectos más significativos del mismo:

Se hace patente la necesidad de actualizar, mediante su reforma, el vigente modelo de financiación autonómica, de acuerdo con los principios de solidaridad, suficiencia, equidad, transparencia y corresponsabilidad fiscal. Los acuerdos del CPFF no consiguen reducir el déficit, llegando a ser la situación preocupante.

La Comunidad Valenciana no resulta favorecida con el actual modelo de financiación. Se halla en la última posición en ingresos per cápita durante la última década, su financiación por habitante es sustancialmente menor que la media.

Las líneas reformistas actuales abogan por incrementar el espacio fiscal propio de la Comunidad Valenciana y el grado de corresponsabilidad fiscal en la gestión tributaria o eliminar los "múltiples y complejos" fondos impuestos por anteriores modelos estableciendo mejoras y "compromisos" en el suministro de información. Un incremento de la corresponsabilidad fiscal no es aconsejable a través de la vía del establecimiento de tributos propios, debido a su bajo potencial recaudatorio.

Es más factible la posibilidad de incrementar la corresponsabilidad fiscal mediante el aumento de los porcentajes de cesión de los tributos estatales como el IRPF 
(porcentaje máximo del 60 por ciento). El instrumento adecuado para la consecución de ese objetivo son las leyes de cesión de tributos del Estado.

Es necesaria una mayor concreción en el Estatuto de autonomía valenciano, en aras a dotar de mayor seguridad jurídica la regulación concerniente a la financiación autonómica. Esencial resulta asimismo la modificación de la LOFCA en aquellos aspectos relativos a la supresión y/o simplificación de la multitud de fondos existentes en la actualidad, regulados en los artículos 13 y siguientes. Además de las propuestas formuladas por los distintos Comités, la citada norma debería incluir la obligatoriedad de reuniones periódicas del Consejo de Política Fiscal y Financiera

En lo referente al gasto sanitario, el problema principal es su desmesurado crecimiento; la Comunidad Valenciana presenta niveles muy elevados, por encima de la media del resto de CCAA. Las propuestas de reforma del sistema de financiación incluyen este aspecto e incluyen medidas en aras a su racionalización.

Con el fin de asegurar la efectiva aplicación del principio de igualdad de los ciudadanos, independientemente del lugar de residencia (propuesto por el Comité de Expertos del Alto Consejo Consultivo) y de acuerdo con el articulo 19 de la CE, podría estipularse la aprobación de un paquete de medidas consistentes en la concesión de beneficios fiscales a las personas físicas que realicen actividades económicas y trasladen su residencia a la Comunidad Valenciana; el cauce para su adopción es su inclusión en la Ley 21/2001, de 27 de diciembre.

El problema del gasto sanitario en la Comunidad Valenciana y su sosteniblidad es un clamor constante en la totalidad de informes emitidos por los distintos comités de expertos sobre la reforma del sistema de financiación.

El concierto, en la Comunidad Valenciana, como forma de gestión indirecta de los servicios sanitarios es motivo de preocupación por el legislador; es partidario de la desaparición de empresas privadas en pro de la prestación de servicios por entidades sin ánimo de lucro, para asegurar la sostenibilidad del sistema.

A favor del concierto por entidades del "tercer sector" se encuentra la normativa comunitaria (Directiva 2014/24/UE). Por nuestra parte, nos mostramos partidarios del concierto con entidades privadas sin ánimo de lucro, pero en ningún caso en exclusiva. Podrían tener cabida entidades con y sin ánimo de lucro y aquellas otras entidades que forman parte de la economía social, como son las cooperativas; las razones son, entre otras, su capacidad de adaptación a los cambios sociales y laborales, especialmente a los producidos como consecuencia de la crisis económica.

Nuestra propuesta es una fórmula mixta en el marco de la Ley 7/2017, siempre que se gestionen servicios de interés colectivo o de titularidad pública; la prestación de los servicios sanitarios concertados por una cooperativa calificada sin ánimo de lucro.

\section{BIBLIOGRAFIA}


ABELLA'N PERPINÁN, J. M. (2013). “El sistema sanitario público en España y sus Comunidades Autónomas. Sostenibilidad y reformas”. Fundación BBVA, Madrid, 2013.

ALCALDE, A. H., CARBONELL, J. R. H. ; RODRÍGUEZ, C. V. (2010). "La reforma de la financiación autonómica de 2009”. Revista d'estudis autonòmics i federals, $\mathrm{N}^{\circ} 11$.

ARCE, V. M. A. ; RADA, A. A. (2013). "Las cooperativas de utilidad pública e iniciativa social. Aspectos administrativos y fiscales”. Boletín de la Asociación internacional de Derecho Cooperativo, $\mathrm{N}^{\circ} 47$.

ARENAS DIAZ, C. A. (2013). "Eficiencia de las Concesiones Administrativas Sanitarias de la Comunidad Valenciana”. Sedisa Siglo XXI.

CALERO MARTINA, R.; GALLARZA. G. (2010). "La concesión administrativa como modelo de gestión sanitaria en la Comunidad Valenciana". Cuadernos de CC.EE. y EE., $\mathrm{N}^{\circ} 59$.

CALONGE, S.; RODRÍGUEZ, M. (1998). "Consecuencias distributivas y de equidad de las políticas de gasto y financiación de la sanidad.” Papeles de economía española, $\mathrm{N}^{\mathrm{o}} 76$.

CANTARERO PRIETO, D. (2006). La financiación del gasto sanitario desde la perspectiva de la experiencia comparada. Fundación BBVA.

CANTARERO PRIETO, D. (2005). "La nueva financiación sanitaria en España: descentralización y prospectiva”. Documento de Trabajo No 196/2005. Fundación de las Cajas de Ahorros.

CARRASCO CANALS, C.( 1989). "Las transferencias de competencias de titularidad estatal en las comunidades autónomas: los casos de Canarias y Valencia”. Revista de Administración Publica, No 120. Septiembre-diciembre.

CUENCA GARCÍA, A. (2014). “Autonomía y corresponsabilidad. La política tributaria de las Comunidades Autónomas de régimen común”. Papeles de economía española, $\mathrm{N}^{\mathrm{o}} 139$.

DE JUAN PENALOSA, J. L. (1979). "El principio de solidaridad interregional. El principio de solidaridad y la regionalización de los impuestos". Documentación Administrativa $\mathrm{N}^{0}$ 181, Madrid.

DE LA FUENTE, A. (2010). "El nuevo sistema de financiación regional: un análisis crítico y proyecciones para 2009”. Universitat Autònoma de Barcelona, Departament d'Economia i d'Història Econòmica, Unitat Fonaments de l'Anàlisi Econòmica. 
DE LA FUENTE. A. (2012). “Sobre el Pacto Fiscal y el sistema de Concierto”. Publicaciones fundación SEPI, Madrid.

DELGADO TELLEZ. M; J. PEREZ. J. (2016). "La financiación de las Comunidades Autónomas más allá del sistema de financiación autonómica". Fedea Policy Papers - 2016/22.

FERRERIRO, A.; BAKAIKOA, B. (1997). "La financiación impositiva comparada: territorios forales versus CCAA de régimen común”. Ponencia presentada en I Congreso de Ciencia Regional de Andalucía: Andalucía en el umbral del siglo XXI. 23-25 de abril, 1997. Jerez de la Frontera y Universidad de Cádiz. Actas del congreso.

GARCÍA MORILLO, J.; PEREZ TREMPS, P.; ZORNOZA PEREZ, J. (1998). Constitución y financiación autonómica. Tirant lo Blanc Alternativa, Valencia.

GÓMEZ DE LA TORRE DEL ARCO, M. (2010). "Las Etapas de la financiación autonómica. Un nuevo sistema de financiación”. Anuario Jurídico y Económico Escurialense, $N^{\circ} 43$.

GRANELL, F. (2016). "Algunas ideas sobre la reforma del sistema de financiación autonómica”. Fedea Policy Papers - 2016/10.

LA CRUZ RODRIGUEZ, B. (2000). “La solidaridad interterritorial en España”. Servicio de publicaciones de la Universidad de Extremadura.

LAGO PEÑAS, S. (2009). "La autonomía tributaria de las Comunidades Autónomas de régimen común: Por qué y cómo avanzar”. Revista de estudios regionales, $\mathrm{N}^{\mathrm{o}}$ VIII.

LAGO PEÑAS, S. Coord. (2007). La financiación del Estado de las autonomías. Perspectivas de futuro. Ministerio de Hacienda. Instituto de Estudios Fiscales.

LÓPAZ PÉREZ A. M. (2014). "Situación actual y perspectivas de futuro para la financiación de la Comunidad Valenciana”, en ADAME MARTÍNEZ, F; RAMOS PRIETO, J. Coord. (2014). Estudios sobre el sistema tributario actual y la situación financiera del sector público: Homenaje al Profesor Dr. D. Javier Lasarte Álvarez. Instituto de Estudios Fiscales, Madrid.

LÓPAZ PÉREZ, A. M. (2009). La hacienda autonómica. Una propuesta alternativa para la Comunidad Valenciana. Bosch. S. L, Barcelona.

LÓPAZ PÉREZ, A. M. (2016). “La financiación de las Comunidades Autónomas y la crisis del estado autonómico: Escenarios de reforma” en V encuentro de Derecho Financiero y Tributario (2. ${ }^{a}$ parte). Documentos - Instituto de Estudios Fiscales, $N^{\circ} .14$, 2016. 
LÓPEZ I CASASNOVAS, G. (2007). “La descentralización fiscal en España en la disyuntiva de la nueva financiación autonómica. Algunas reflexiones generales y específicas al caso de la sanidad”. Revista de Estudios Regionales, № 78.

LÓPEZ I CASASNOVAS, G. (2016) "La descentralización sanitaria, la cohesión social y el buen funcionamiento del sistema de salud. Mediterráneo económico”. Colección Health Policy Papers, 2016 /10.

LÓPEZ I CASASNOVAS, G.; CASADO MARÍN, D. (1996). “La financiación de la sanidad pública española: aspectos macroeconómicos e incidencia en la descentralización fiscal”. Presupuesto y gasto público, N No $^{\circ}$.

LÓPEZ LABORDA, J. (2006). Veinticinco años de financiación autonómica: balance y perspectivas. Departamento de Economía Pública, Universidad de Zaragoza.

LÓPEZ LABORDA, J. (2014). "Sugerencias para una reforma de la regulación constitucional de la financiación autonómica”. Fedea Policy Papers - 2014/02.

MAINAR CABANES, E. (2010). “La peculiar vía valenciana a la autonomía”. Historia Actual On Line, $N^{\circ} 21$.

MARIN FERRER, M.; DE ROSA TORNER, A. (2007). “Las nuevas formas de gestión sanitaria «modelo Alzira»”. Instituto de Estudios Económicos.

MARTIN QUERALT, J.; LOZANO SERRANO, C. (2007). Curso de Derecho Financiero y Tributario. Tecnos, Madrid.

MENENDEZ MORENO. A. (2005). "El marco constitucional de la financiación de las Comunidades Autónomas” en La reforma de los Estatutos de Autonomía, Junta de Castilla y León.

MENENDEZ REXACH, A. (2008). "La gestión indirecta de la asistencia sanitaria pública. Reflexiones en torno al debate sobre la privatización de la sanidad”. Revista Administración Sanitaria No 6 (Vol. 2).

NAVARRO GARCÍA, A. (2014). El copago como mecanismo de financiación de los servicios del Estado social: problemas jurídicos. Tesis doctoral. Publicaciones de la Universidad de Gerona.

PRIETO, D. C. ; GÓMEZ, N. F. (2003). Análisis del gasto sanitario autonómico y su nueva financiación en España. Ministerio de Hacienda, Instituto de Estudios Fiscales.

REGUERA, E. G.; RUIZ, J. L. G. (2001). "Los sistemas forales de concierto y convenio económico como factor diferencial en el Estado Autonómico” en GUERRA, 
L. M. L., Estudios de Derecho Constitucional: homenaje al profesor D. Joaquín García Morillo. Tirant lo Blanch, Valencia.

RODRIGUEZ BEREIJO, A. (2005). "Breve reflexión sobre los principios constitucionales de justicia tributaria”. Revista jurídica Universidad Autónoma de Madrid, $\mathrm{N}^{\mathrm{o}} 13$.

RODRIGUEZ BEREIJO, A. (2011). Igualdad tributaria y tutela constitucional. Un estudio de jurisprudencia (Igualdad tributaria del art. 31.1 CE e igualdad ante la ley del art. 14 CE: el problema del recurso de amparo en materia tributaria). Marcial Pons, Barcelona.

SÁNCHEZ BAYLE, M. (2014). "La privatización de la asistencia sanitaria en España”. Documento de trabajo 182/2014. Fundación Alternativas.

SÁNCHEZ MALDONADO, J.; ORDÓÑEZ DE HARO, C.; MOLINA GARRIDO, C. (2007). "La reforma de la financiación autonómica: un escenario de reparto de los recursos basado en las necesidades de gasto". Revista de Estudios Regionales, $\mathrm{N}^{\mathrm{o}} 78$ ).

TUDELA ARANDA, J. ( 2016). El fracasado éxito del estado autonómico. Una historia española. Marcial Pons, Madrid.

VILLALTA. M. (2016). "Pasado, presente y futuro de la nivelación en el modelo de financiación de las Comunidades Autónomas”. Fedea Policy Papers - 2016/16.

ZUBIRI, I. (2016). “El Sistema de Financiación de las CC.AA.: Problemas y Propuestas de Solución”. Fedea Policy Papers - 2016/18. 